\title{
Crystal structure of a complex between the electron-transfer partners arsenite oxidase and cytochrome c552, from the arsenite respiring bacterium Rhizobium sp. NT-26
}

\author{
Nilakhi Poddar ${ }^{1}$, Joanne M Santini' ${ }^{2}$, Megan J Maher ${ }^{1,3}$
}

${ }^{1}$ School of Chemistry and The Bio21 Instittute Molecular Sciences and Biotechnology Institute, The University of Melbourne, Parkville, 3052, Australia; ${ }^{2}$ Institute of Structural and Molecular Biology, Division of Biosciences, University College London, London WC1E 6BT, United Kingdom; ${ }^{3}$ Department of Biochemistry and Genetics, La Trobe Institute for Molecular Science, La Trobe University, Melbourne, Australia

nilakhip@student.unimelb.edu.au

Arsenic is a widely distributed toxic metalloid that poses a significant threat to human health by contaminating ground water systems [1]. Arsenic can exist in both organic and inorganic forms, with arsenite $\left(\mathrm{AsO}_{3}{ }^{3-}\right)$ and arsenate $\left(\mathrm{AsO}_{4}{ }^{3-}\right)$, being toxic species. Although arsenic is hazardous to human health, some prokaryotes have developed unique mechanisms that utilise arsenite $\left(\mathrm{AsO}_{3}{ }^{3-}\right)$ and arsenate $\left(\mathrm{AsO}_{4}{ }^{3-}\right)$ for respiration and therefore as energy sources.

The organism Rhizobium sp. NT-26, respires with arsenite and employs the arsenite oxidase enzyme (Aio) for its crucial respiratory activity, which catalyzes the oxidation of arsenite $\left(\mathrm{AsO}_{3}{ }^{3-}\right)$ to arsenate $\left(\mathrm{AsO}_{4}{ }^{3-}\right)$. The Aio enzyme consists of a large catalytic subunit (AioA), which contains a molybdenum centre and a $3 \mathrm{Fe}-4 \mathrm{~S}$ cluster, and a small subunit (AioB) containing a Rieske $2 \mathrm{Fe}-2 \mathrm{~S}$ cluster. Arsenite is oxidized to arsenate at the Mo site,concomitantly reducing Mo(VI) to Mo(IV) [2]. The electrons are then passed to the $3 \mathrm{Fe}-4 \mathrm{~S}$ cluster, the Rieske cluster in AioB and finally to an electron acceptor, which is cytochrome $c_{551}$ (cyt $\left.c_{551}\right)[2,3]$. Structures of interprotein transfer complexes are interesting as they form via extensive electrostatic interactions, which are highly transient. Structural flexibility at the protein-protein interface promotes fast dissociation of the complex following electron transfer [4]. To date, the structure of the Aio and cyt $c_{551}$ complex has not been investigated, and the kinetics and thermodynamics of the Aio to cyt $c_{551}$ interaction are unknown. In this study, we describe the structure of the Aio/cyt $c_{551}$ complex, determined by X-ray crystallography. The structure provides insight into various types of interactions (hydrogen bonding, salt bridges and electrostatic interactions) of the complex that can be studied further to understand the mechanism and specificity between the partner proteins during electron transfer.

[1] H. V. Aposhian, and M. M. Aposhian, “Arsenic toxicology: five questions,” Chem Res Toxicol, vol. 19, no. 1, pp.1-15, Jan, 2006.

[2] T. P. Warelow, M. Oke, B. Schoepp-Cothenet, J. U. Dahl, N. Bruselat, G. N. Sivalingam, S. Leimkühler, K.

Thalassinos, U. Kappler, and J. H. Naismith, "The respiratory arsenite oxidase: structure and the role of residues surrounding the rieske cluster," PLoS One, vol. 8, no. 8, pp. e72535, 2013.

[3] P. J. Ellis, T. Conrads, R. Hille, and P. Kuhn, "Crystal structure of the $100 \mathrm{kDa}$ arsenite oxidase from Alcaligenes faecalis in two crystal forms at $1.64 \AA$ and $2.03 \AA$,’ Structure, vol. 9, no. 2, pp. 125-132, 2001.

[4] D. Leys, and N. S. Scrutton, "Electrical circuitry in biology: emerging principles from protein structure," Curr Opin Struct Biol, vol. 14, no. 6, pp. 642-7, Dec, 2004.

Keywords: X-ray crystallography, arsenic, interprotein electron transfer complex 